\title{
Flexibility of the power system: background, relevance, and categorization
}

\author{
Dmitry Efimov ${ }^{1,2, *}$ \\ ${ }^{1}$ Melentiev Energy Systems Institute, Electric Power System Department, 664033 Irkutsk, Russia \\ ${ }^{2}$ Irkutsk National Research Technical University, Energy Institute, 664074 Irkutsk, Russia
}

\begin{abstract}
The definitions of flexibility and the place of flexibility in the structure of the main general properties of energy systems are given. The factors and trends are indicated, which determine the appearance of current energy systems, and even more future energy systems. The emerging trends will require a revision of the principles and means of power system management and control towards increasing the flexibility. Based on these factors, it is possible, firstly, to analyse flexibility as a complex property, using differentiation by aspects and categories, and, secondly, to determine and categorize the means of ensuring flexibility. The paper concludes with the European energy regulators' view of flexibility as a marketable service.
\end{abstract}

\section{Definitions of flexibility}

In the early 80 s of the last century academician L.A. Melentiev formulated the foundations of the systematic approach for energy. He defined the flexibility of power systems as the ability of a system to change its structure with the necessary speed to ensure the normal performance of its functions (development in the required scales and over periods of time, operation at possible disturbances) [1]. At the same time, the implementation of the property of flexibility in the control processes of the system means the choice of such a direction of its movement, which will most closely correspond to the possibilities of its optimal development and operation under insufficiently defined conditions in advance.

According to L.A. Melentyev, flexibility is included in the complex property of movement along with dynamism and efficiency (Fig. 1). The movement of energy systems is subject of human coordination and includes the development and operation. The movement should always be in equilibrium in the sense of both ensuring the compliance of the produced and consumed products (the type of energy produced, energy resource), and changes in the system state under the influence of internal and external factors (disturbances).

Flexibility is a complex property that combines three single properties [1]:

- Inertia as the ability of a system to withstand external and internal impacts that aim to change its previously planned movement.

- Adaptation as the ability of a system to adapt its movement to the appearance of relatively short-term external and internal disturbances (new conditions affecting the development of systems).

- Reliability as the ability of a system to perform its functions within the specified limits.

In 1995, the CIGRE (International Council on Large Electrical Systems) working group characterized flexibility as the ability to adapt the planned development of the power system, quickly and at reasonable cost, to any change, foreseen or not, in the conditions which prevailed at the time it was planned [2]. As can be seen, the definition does not cover the operation of a power system.

By now, there are a number of definitions of flexibility proposed by authoritative energy organizations. Table 1 summarizes some of them.

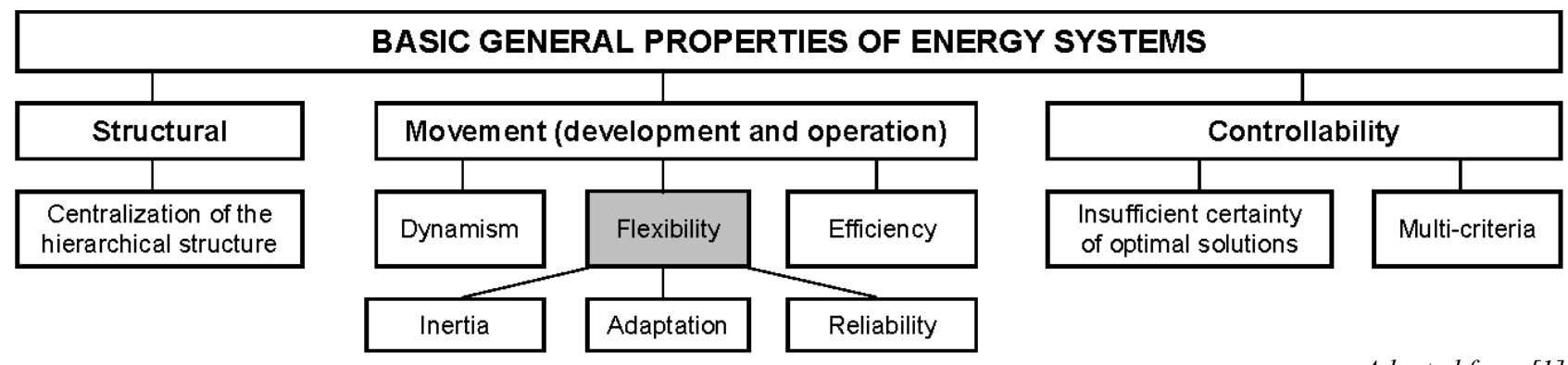

Fig. 1. Basic general properties of energy systems.

\footnotetext{
* Corresponding author: d.n.efimov@mail.ru
} 
Table 1. Definitions of power system flexibility 2011-2018.

\begin{tabular}{|c|c|}
\hline Organization, Year, [Reference] & Definition \\
\hline IEA (the International Energy Agency), 2011, [3] & $\begin{array}{l}\text { The extent to which a power system can modify electricity production or } \\
\text { consumption in response to variability, expected or otherwise. In other words, } \\
\text { it expresses the capability of a power system to maintain reliable supply in the } \\
\text { face of rapid and large imbalances, whatever the cause. }\end{array}$ \\
\hline $\begin{array}{l}\text { International expert group, 2013, [4] } \\
\text { (for IEEE Power and Energy Magazine) }\end{array}$ & $\begin{array}{l}\text { The ability to accommodate the variability and uncertainty in the load- } \\
\text { generation balance while maintaining satisfactory levels of performance for } \\
\text { any time scale }\end{array}$ \\
\hline $\begin{array}{l}\text { EURELECTRIC (the European Union of the } \\
\text { Electricity Industry), 2014, }[5,6]\end{array}$ & $\begin{array}{l}\text { The modification of generation injection and/or consumption patterns in } \\
\text { reaction to an external signal (price signal or activation) in order to provide a } \\
\text { service within the energy system }\end{array}$ \\
\hline $\begin{array}{l}\text { EPRI (the Electric Power Research Institute), } \\
\text { 2016, [7] }\end{array}$ & $\begin{array}{l}\text { The ability to adapt to dynamic and changing conditions, for example, } \\
\text { balancing supply and demand by the hour or minute, or deploying new } \\
\text { generation and transmission resources over a period of years }\end{array}$ \\
\hline $\begin{array}{l}\text { ETSO-E (the European Transmission System } \\
\text { Operators), 2017, [8] }\end{array}$ & $\begin{array}{l}\text { The active management of an asset that can impact system balance or grid } \\
\text { power flows on a short-term basis, i.e. from day-ahead to real-time }\end{array}$ \\
\hline $\begin{array}{c}\text { European Distribution System Operators, 2018, } \\
{[9]} \\
\text { (based on }[5,6])\end{array}$ & $\begin{array}{l}\text { The modification of generation injection and/or consumption patterns, on an } \\
\text { individual or aggregated level, often in reaction to an external signal, in order } \\
\text { to provide a service within the energy system or maintain stable grid operation }\end{array}$ \\
\hline $\begin{array}{c}\text { CEER (the Council of European Energy } \\
\text { Regulators), 2018, [10] } \\
\text { (the final conclusions on the above definitions) }\end{array}$ & $\begin{array}{l}\text { The capacity of the electricity system to respond to changes that may affect } \\
\text { the balance of supply and demand at all times }\end{array}$ \\
\hline $\begin{array}{c}\text { IEA (the International Energy Agency), 2018, } \\
{[11]} \\
\text { (revised definition) }\end{array}$ & $\begin{array}{l}\text { All relevant characteristics of a power system that facilitates the reliable and } \\
\text { cost- effective management of variability and uncertainty in both supply and } \\
\text { demand }\end{array}$ \\
\hline $\begin{array}{l}\text { IRENA (The International Renewable Energy } \\
\text { Agency), 2018, [12] }\end{array}$ & $\begin{array}{l}\text { The capability of a power system to cope with the variability and uncertainty } \\
\text { that VRE (variable renewable energy) generation introduces into the system } \\
\text { in different time scales, from the very short to the long term, avoiding } \\
\text { curtailment of VRE and reliably supplying all the demanded energy to } \\
\text { customers }\end{array}$ \\
\hline
\end{tabular}

Based on [16]

Most of these definitions, in contrast to the CIGRE definition, refer specifically to the operation of the power system, specifically - to maintaining the balance of supply and demand. Depending on the considered time interval, they mean power balances, energy balances or both. A minority of the authors relate flexibility to any time interval, covering both the operation and development of the power system.

The most recent (third) revision of the IEA definition is also invariant to the time horizon, where the ability of a power system to reliably and cost-effectively manage the variability and uncertainty of demand and supply across all relevant timescales, from ensuring instantaneous stability of the power system to supporting long-term security of supply [13-15].

The first attempt to generalize those given in Table 1 and a number of other available definitions of flexibility were made by CEER [10] (see the table), which, in general, initiated the relevant discussions and formulations. The next attempt was made by ISGAN (the International Smart Grid Action Network, which is a Technology Collaboration Programme of the IEA) and led to an even more abstract formulation: "Flexibility relates to the ability of the power system to manage changes" [16].
Obviously, the next step should have been an attempt to detail the definition - preferably, without loss of generality. ISGAN concluded that flexibility should considered as a complex property, the specificities of which are different depending on the aspect of consideration. Such differentiation of the flexibility property depending on the needs of the power system and its elements (as well as the classification of these needs themselves) were carried out by ISGAN on specific aspects and categories [16] and will be presented in Section 3 of this paper.

\section{Increased need for flexibility}

Despite the fact that the concept of flexibility as a property of energy systems has existed for a long time, interest in it (including primarily among practitioners in power engineering) has arisen relatively recently. This was due to a number of factors and trends (see Fig. 2) which have become visible in the world's power systems in the last decade and, as can be assumed, will have a decisive influence on the structure and operating conditions of the EPS of the future [17].

The factors shown in the figure, as such can be recognized as positive - the upper group of factors contributes to the development of the electrical network, 
the lower one - to improve the quality of power supply to consumers due to the implementation of new technologies on their side.

Meanwhile, with the wide spread involving these technologies, the degree of influence of consumers on the EPS operation increases significantly, and the emerging trends are already negative. The aggregate conclusion of these trends as two tendencies, which seem to be the most important in terms of their negative impact, is presented in $[17,18]$ :

- Uncontrolled operation of distributed generation at the system level, if its share increases, creates completely new power flows in the system, increases the level of short-circuit currents in emergency conditions, changes voltage profiles in the distribution network and can lead to a decrease in the quality of electricity and the quality of power supply in general.

- The existing principles of control of the EPS operating conditions base on the use of the regulating effect of the load and the frequency characteristics of generation. Due to these effects, the current EPSs have a natural margin of stability, and control systems act when the operating parameters go beyond the established boundaries. The wire spread use of power electronics and rectifier-inverter systems for connection to EPS reduces the regulatory effects and, thus, this natural reserve.

Listed in Fig. 2 factors and trends require significant modification and development of the principles and tools of power system control in order:

1) to neutralize the negative impact of emerging trends,

2) to turn new technical capabilities of consumers to the benefit of the power system in terms of increasing the flexibility of its response to unforeseen disturbance of the operating conditions.

In particular, it seems promising to interact between EPS and consumers for joint control of system conditions using the regulation capabilities of consumers $[17,19]$.

FACTORS

TRENDS

Scaling up EPS

generation,
Using distributed

\begin{tabular}{|c|c|}
\hline $\begin{array}{c}\text { Growth in the share of active } \\
\text { consumers (including prosumers) }\end{array}$ & $\begin{array}{c}\text { Growing uncertainty in demand } \\
\text { for power and energy }\end{array}$ \\
\hline
\end{tabular}

\begin{tabular}{|c|c|c|}
$\begin{array}{c}\text { Connecting consumers } \\
\text { via rectifiers and voltage stabilizers }\end{array}$ \\
\hline $\begin{array}{c}\text { Application of transformers } \\
\text { with on-load tap-changers }\end{array}$
\end{tabular}

Fig. 2. Factors and trends that determine the shape of the EPS of the future. 


\section{Categorization of flexibility}

Based on the above factors, one can, first, analyse flexibility as a complex property, using differentiation by aspects and categories, and, second, define and categorize the means of ensuring flexibility.

Flexibility can be differentiated (according to and in development of the approach [16]) in the following aspects (see Fig. 3):

- The Functional aspect contains categories of flexibility in terms of physical parameters (power, energy, transfer capacity, and voltage).

- The Territorial dimension contains a system-wide flexibility category (in terms of stability, frequency, and reliable power supply) and a regional and local category (in terms of transfer capacity, voltage, and power quality).

- The Temporal aspect is categorised by time intervals during operation and planning the development of the power system: from fractions of a second (for maintaining stability and frequency) to minutes and hours (for heat loads and generation scheduling), and, further, up to months and years (for accounting seasonal changes, planning new investments in the development of the system, etc.).

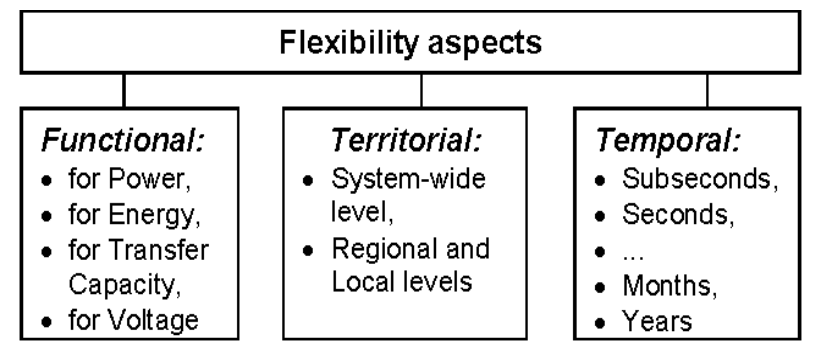

Fig. 3. Aspects and categories of flexibility.

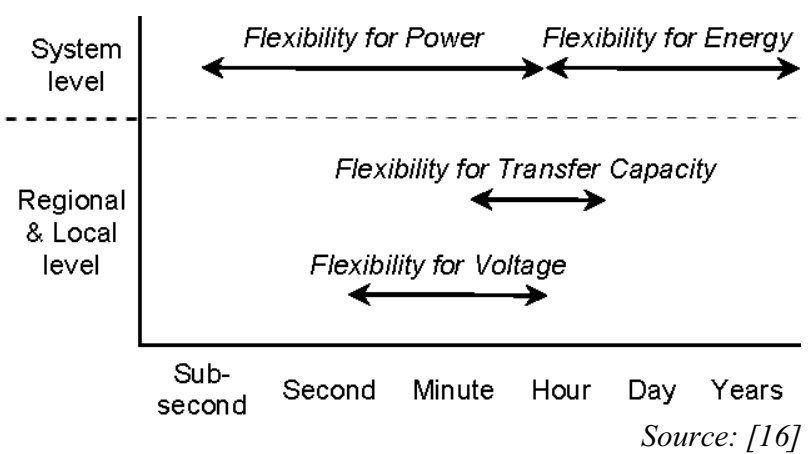

Fig. 4. Interrelation of flexibility needs in perspectives of space (local/regional to system level) and time.

Fig. 4 illustrated the mutual correspondence of the categories of the three aspects of flexibility. In this case:

- Comparison of the categories of functional and territorial aspects of flexibility allows you to correlate flexibility in power and energy with the system-wide level, and flexibility in transfer capacity and voltage with regional or local levels (for more details, see Table 2).

- Comparison of the categories of functional and temporal aspects of flexibility resolves the issue of quantitative measures of flexibility - depending on the aspect and category, flexibility will be measured in megawatts, kilowatt-hours, kilovolts, seconds, etc.

The proposed categorization is applicable to specific flexibility tools. Such tools are often multifunctional (correlated with more than one category of functional aspect) and can be categorized accordingly in other aspects. As an example, we can cite such means of ensuring flexibility as energy storage devices of various types or, even more broadly, methods and means of storing any energy resource. With all the variety of such tools, they can easily be categorised in accordance with the proposed aspects.

Table 2. Categorization of flexibility in functional, territorial and temporal aspects.

\begin{tabular}{|c|c|c|c|c|}
\hline $\begin{array}{c}\text { Functional } \\
\text { aspect }\end{array}$ & $\begin{array}{l}\text { Territori } \\
\text { al level }\end{array}$ & Need description & Main rationale & $\begin{array}{l}\text { Activation } \\
\text { timescale }\end{array}$ \\
\hline for Power & \multirow{2}{*}{$\begin{array}{l}\text { System- } \\
\text { wide }\end{array}$} & $\begin{array}{l}\text { Short term equilibrium between power } \\
\text { supply and power demand (a system-wide } \\
\text { requirement for maintaining the frequency } \\
\text { stability) }\end{array}$ & $\begin{array}{l}\text { Increased amount of intermittent, } \\
\text { weather dependent, power supply } \\
\text { in the generation mix }\end{array}$ & $\begin{array}{l}\text { Fractions of } \\
\text { a second up } \\
\text { to an hour }\end{array}$ \\
\hline for Energy & & $\begin{array}{l}\text { Medium to long term equilibrium between } \\
\text { energy supply and energy demand (a } \\
\text { system wide requirement for demand } \\
\text { scenarios over time) }\end{array}$ & $\begin{array}{l}\text { Decreased amount of fuel } \\
\text { storage-based energy supply in } \\
\text { the generation mix }\end{array}$ & $\begin{array}{l}\text { Hours to } \\
\text { several } \\
\text { years }\end{array}$ \\
\hline $\begin{array}{l}\text { for Transfer } \\
\text { Capacity }\end{array}$ & \multirow[b]{2}{*}{$\begin{array}{l}\text { Regional } \\
\text { and Local }\end{array}$} & $\begin{array}{l}\text { Short to medium term ability to transfer } \\
\text { power between supply and demand, where } \\
\text { local or regional limitations may cause } \\
\text { bottlenecks resulting in congestion costs }\end{array}$ & $\begin{array}{l}\text { Increased utilisation levels, with } \\
\text { increased peak demands and } \\
\text { increased peak supply }\end{array}$ & $\begin{array}{l}\text { Minutes to } \\
\text { several } \\
\text { hours }\end{array}$ \\
\hline for Voltage & & $\begin{array}{l}\text { Short term ability to keep the bus voltages } \\
\text { within predefined limits (a local and } \\
\text { regional requirement) }\end{array}$ & $\begin{array}{l}\text { Increased amount of distributed } \\
\text { power generation in the } \\
\text { distribution systems, resulting in } \\
\text { bi-directional power flows and } \\
\text { increased variance of operating } \\
\text { scenarios }\end{array}$ & $\begin{array}{l}\text { Seconds to } \\
\text { tens of } \\
\text { minutes }\end{array}$ \\
\hline
\end{tabular}




\section{EPS flexibility as a service: the vision of European regulators (based on the materials of the CEER report [20])}

In the distribution network, providing flexibility on the part of its operator (DSO) could lead to more rational use and increase of network capacity and thus delay or (if cost-effective) become an alternative to traditional network strengthening [20]. The CEER report focuses on the network operator acquiring flexibility services (primarily in terms of congestion management) in order to improve the efficiency and development of the distribution network.

Congestion in a broad sense refers to the state of the system in which one or more restrictions (on heating, on voltage, on stability) prevent the transfer of the required power. Congestions in a distribution network arise from overvoltage or overloading of network components in terms of current or power [21]. Technically, congestion reductions have been achieved at the planning stage through reinforcement of the network, and at the operational stage through voltage or load/generation control. Note that new construction to increase network capacity in many cases turns out to be impossible or unjustified from different points of view.

Organizational congestion management methods are aimed at changing consumer behaviour (load schedules) and are implemented through connection agreements, tariff structure, market purchases (with direct payments to change the behaviour of the network user) together or separately with regulations and rules [20]. In case of low efficiency or market failure, administrative approaches may be used. Thus, the DSO has a set of options (see Fig. 5), including network reinforcement (all types of investments to increase network transfer capacity) and access to flexibility within the listed categories or a combination of these to address an emerging network problem. Given the emerging market for operational flexibility, flexibility resources can compete with each other with their specific technical advantages and constraints [16].
A number of pilot and demonstration projects are underway to implement flexibility as a service to the network operator. The scale of projects is different, and most of them are still in their early stages. The UK is among the leaders, where all DSOs are already conducting flexibility tenders in the prescribed manner, collecting applications in accordance with a predefined specification of network needs.

Regarding the legal and regulatory framework, regulations in many CEER member states do not prevent the DSO from accessing market-based procurement flexibility. Recently (in 2019), Directive 2019/944 of the European Union on internal electricity markets [22] was issued, one of the articles of which regulates the relationship between the distribution network operator and flexibility service providers.

It is important to note that any assets in the power system (power plants, power grids, energy storage, consumer-regulators and distributed energy resources, including renewables) can act as providers of flexibility services, while ensuring that all classes of power system assets are able to receive fair remuneration for the flexibility services they are capable of providing [13].

Several countries (e.g. Australia, Ireland, Spain and the United States) have introduced market reforms and regulations that activate VRE flexibility [13].

These provisions were reinforced in Directive 2019/944 with the emphasis, that the regulatory framework shall ensure, that distribution system operators are able to procure such services from providers of distributed generation, demand response or energy storage and shall promote the uptake of energy efficiency measures, where such services cost-effectively alleviate the need to upgrade or replace electricity capacity and support the efficient and secure operation of the distribution system [22].

This work was supported by the Russian Scientific Foundation under the project No. 19-49-04108 "Development of Innovative Technologies and Tools for Flexibility Assessment and Enhancement of Future Power Systems".

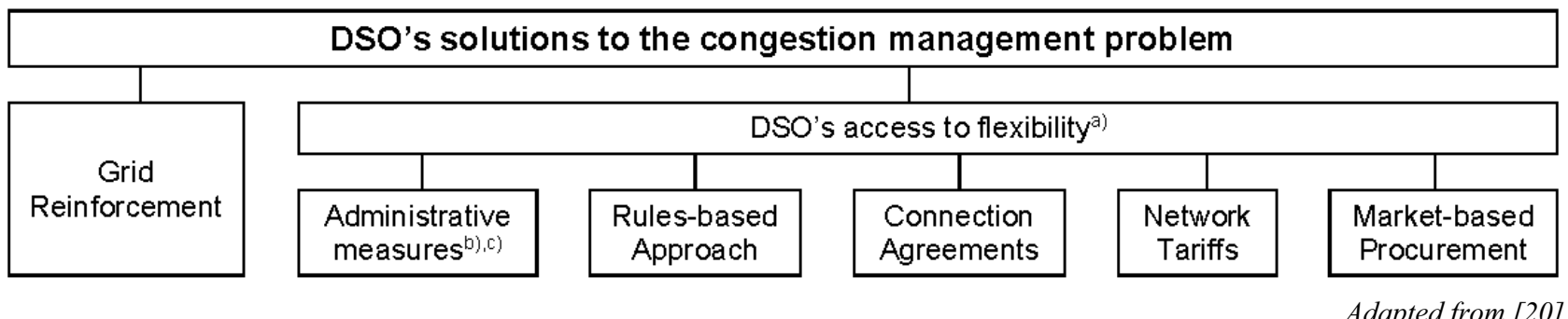

Fig. 5. Possible solutions to the problem of congestion management.

Adapted from [20]

Notes [20]:

a) Categories are not mutually exclusive.

b) The key element of administrative measures is that the price for ensuring network flexibility is not determined by market participants or through a market procedure (for example, on a trading platform or through an auction mechanism), but taking into account regulatory requirements regarding costs of the flexibility supplier.

c) Administrative interaction can also mean that the DSO has direct operational control to change the behaviour of the object causing the overload. 


\section{References}

1. Melentiev L.A. Systems research in energy. $2^{\text {nd }}$ ed., Add. Moscow: Nauka, 1983.455 p. (in Russian)

2. CIGRE Working Group 37.10, "Methods for planning under uncertainty - towards flexibility in power system development," Electra, vol. 161, pp. 143-163, 1995.

3. IEA, "Harnessing variable renewables - a guide to the balancing challenge," 2011.

4. H. Holttinen, A. Tuohy, M. Milligan, E. Lannoye, V. Silva, S. Müller and L. Söder, "The flexibility workout: managing variable resources and assessing the need for power system modification," IEEE Power and Energy Magazine, vol. 11, p. 53-62, 2013.

5. Eurelectric, "Flexibility and Aggregation Requirements for their interaction in the market," 2014.

6. European Commission Smart Grids Task Force Expert Group 3 - Regulatory Recommendations for Smart Grids Deployment, "Regulatory Recommendations for the Deployment of Flexibility," 2015.

7. EPRI, "Electric Power System Flexibility: Challenges and Opportunities," 2016.

8. ENTSO-E, "ENTSO-E Response to the CEER Public Consultation Guidelines of Good Practice for Flexibility Use at Distribution Level," 2017.

9. CEDEC, EDSO for smart grids, Eurelectric, GEODE, "Flexibility in the energy transition - A Toolbox for Electricity DSOs," 2018. [Online]. Available:

https://www.edsoforsmartgrids.eu/flexibility-in-theenergy-transition-a-toolbox-for- electricity-dsos/.

10. Council of European Energy Regulators Distribution Systems Working Group, "Flexibility Use at Distribution Level - A CEER Conclusions Paper, Ref: C18-DS-42- 04," 2018.

11. IEA, "Status of Power System Transformation 2018:
Advanced Power Plant Flexibility," IEA, Paris, 2018.

12. International Renewable Energy Agency (IRENA), "Power System Flexibility for the Energy Transition, Part 1: Overview for policy makers," IRENA, Abu Dhabi, 2018.

13. IEA, "Status of Power System Transformation 2019: Power system flexibility," IEA, Paris, 2019. 30 p.

14. IEA and 21CPP. Status of Power System Transformation 2018 - Advanced Power Plant Flexibility, Paris, 2018.

15. IEA (International Energy Agency). China Power System Transformation - Assessing the Benefit of Optimised Operations and Advanced Flexibility Options, Paris, 2019.

16. Hillberg E., e.a. Flexibility needs in the future power system: ISGAN Annex 6 Power T\&D Systems, Discussion paper, March 2019. - 47 p. DOI: 10.13140/RG.2.2.22580.71047

17. Voropai N.I., Osak A.B. Electric power systems of the future // Energy Policy, 2014, No. 5. 60-63. (in Russian)

18. Voropai N, Rehtanz C. Flexibility and Resiliency of Electric Power Systems: Analysis of Definitions and Content // EPJ Web of Conferences 217, 01018 (2019), FREPS 2019. 6 p.

19. Voropai N.I., Osak A.B., Senderov S.M., Stennikov V.A. Energy systems as objects of hierarchical modeling // In the book: Hierarchical modeling of energy systems / Ed. N.I. Voropai, V.A. Stennikov; L.A. Melentiev Energy Systems Institute SB RAS. Novosibirsk: Publishing house "Geo", 2020. p. 1329. (in Russian)

20. Distribution Systems Working Group. CEER Paper on DSO Procedures of Procurement of Flexibility. Ref: C19-DS-55-05, 16 July 2020.

21. The Smart Grid - Adapting the Power System to New Challenges, Math H.J. Bollen, 2011.

22. Directive (EU) 2019/944 of the European Parliament and of the Council of 5 June 2019 on common rules for the internal market for electricity. 